\title{
DEATH DUE TO ADULT RESPIRATORY DISTRESS SYNDROME FOLLOWING ASSAULT WITH 'RUBBER ACID': COULD IT HAVE BEEN AVERTED?
}

\author{
Fernando Dinesh M.G. \& Kaluarachchi C.I. \\ Department of Forensic Medicine, Faculty of Medicine, University of Peradeniya.
}

\section{INTRODUCTION}

Adult respiratory distress syndrome and chemical pneumonitis are well documented effects of exposure to chemical fumes. Many organic and non-organic agents cause chemical pneumonitis ${ }^{1}$. The course of the disease depends on the nature of the chemical agent, intensity and duration of the exposure and the interval between exposure and start of treatment ${ }^{2}$. Also the site of damage tends to vary with the gas involved; gases with higher water solubility being effectively scavenged by the upper respiratory mucosa, while insoluble toxic gases have their effects on the lower respiratory mucosa ${ }^{3}$.

Rubber acid refers to both formic acid and acetic $\operatorname{acid}^{4}$. Both acetic acid and formic acid ${ }^{5}$ are used in the rubber industry as a coagulant for natural rubber latex and form making, and as a preservative of latex. Most of the forensic medicine books in Sri Lanka consider rubber acid to be acetic acid ${ }^{6,7}$. However in Sri Lanka, the most commonly used acid in the rubber industry is formic acid ${ }^{8}$ and both formic acid and acetic acid are easily accessible in areas with rubber plantations.

Burns due to acid assault are the most common form of chemical burns in Sri Lanka with most victims being in the young and productive age group ${ }^{8}$.

We report a case of inhalation injury due to 'rubber acid' to highlight the differences between the two acids used, and abused, in the rubber industry.

\section{Case report}

'Rubber acid' had been thrown on the face of a 23 year old, healthy male by three known men. He sustained acid burns on the face, chest and upper limbs. He was admitted to local hospital immediately and was transferred to the National Hospital of Sri Lanka (NHSL) on the same day. $\mathrm{He}$ had no loss of consciousness, fever or breathing difficulty. Burn surface area was calculated to be $14 \%$. As the patient suffered from extensive burn injury to the right eye with involvement of the cornea, he was transferred to the Eye Hospital. On Day 7 the patient developed fever with chills, rigors and cough associated with yellowish sputum and was transferred back to NHSL. On Day 8 he was started on intermittent positive pressure ventilation due to increasing respiratory distress. Swabs from the wound were positive for coliforms and Staphylococcus aureus. On day 12 he developed cardiac arrest with ventricular fibrillation and died.

Post mortem examination revealed acid burns of the right side of the face, neck, front of chest, upper part of the right arm and the middle one third of anterior and posterior aspects of left forearm. Right eye showed extensive acid burns on the eye lid and cornea. Right side of the nose, entire mouth and right ear also had acid burns.

Larynx, trachea and bronchi were congested and filled with thick yellowish secretions. Lungs were heavy and solid with right and left lungs weighing 1200 grams and 1000 grams respectively. Surface of the lungs was nodular with fibrin tags. Cut section showed congested, haemorrhagic lungs with a variegated appearance involving all areas. On examination of the heart a pale area was found in the left ventricle and apex. There was no fibrosis and the valves were normal. A small subarachnoid haemorrhage was found over the left temporal lobe. Liver, spleen, kidneys and supra renal glands were enlarged.

Microscopic examination of the lung showed confluent haemorrhagic bronchopneumonia and diffuse alveolar damage consistent with acute respiratory distress syndrome. Brain showed marked congestion with multiple areas of minute haemorrhages. Other organs were microscopically normal. Death was attributed to adult respiratory distress syndrome due to bilateral bronchopneumonia due to chemical pneumonitis following inhalation injury caused by acid. 


\section{DISCUSSION}

Adult Respiratory Distress Syndrome (ARDS) is a complex clinical, radiological and physiological syndrome. Toxic chemical inhalation, severe bacterial pneumonia and aspiration of stomach contents are well known causes of $\operatorname{ARDS}^{9}$.Both formic acid and acetic acid can cause adult respiratory distress syndrome, but the different chemical properties of the two chemicals may change the course of the disease in each case.

Formic acid $\left(\mathrm{CH}_{2} \mathrm{O}_{2}\right)$ is a volatile, colourless, medium strong acid with a pungent odour ${ }^{10}$. Since the relative density of the vapour/air mixture at $20^{\circ} \mathrm{C}$ is 1.03 , harmful contamination of air can occur rapidly on evaporation of this substance ${ }^{10}$. The evaporation would be more in Sri Lanka, as the normal environment temperature is around 27$30^{\circ} \mathrm{C}$.

Formic acid can be absorbed into the body by ingestion, by inhalation or through the skin. The substance is a severe irritant to the eyes, the skin and the respiratory tract ${ }^{11}$. Formic acid is more caustic to the skin than acetic acid ${ }^{12}$. Skin absorption can cause serious skin burns. Systemic toxicity has been reported in patients who presented with skin burns ${ }^{13}$. Inhalation of the vapour can cause pulmonary oedema, swelling of the airway, and respiratory distress ${ }^{10}$. Pulmonary aspiration with secondary pneumonia may occur. Occasionally direct chemical pneumonitis may also occur ${ }^{14}$. Splashes of formic acid in the eye have caused permanent clouding of the cornea, with loss of visual acuity. Ingestion causes ulceration of the gastrointestinal tract, which results in perforation and peritonitis and late scarring of structures of the gastrointestinal tract. Major complications are acute renal failure and disseminated intravascular coagulation ${ }^{14}$.

Most reported cases of formic acid poisoning in Europe, ${ }^{13}$ India and Sri Lanka involve accidental or intentional ingestion. Due to the volatile nature of the acid, respiratory complications, such as toxic pneumonitis have been reported in patients who presented with formic acid ingestion ${ }^{15,16}$. Mathew and Dalus studied 302 patients admitted with formic acid ingestion and found that $44 \%$ had respiratory distress, $70.2 \%$ had metabolic acidosis, $47.4 \%$ had aspiration pneumonia, $33.8 \%$ had ARDS and $25.5 \%$ had chemical pneumonitis ${ }^{17}$. This shows that respiratory distress is significantly associated with morbidity even in cases of ingestion. Another study reveals that several patients who died due to formic acid ingestion, Sri Lanka Journal of Forensic Medicine, Science \& Law-May 2012-Vol.3 No.1 had evidence of widespread pneumonitis at autopsy $^{16}$. Formic acid inhalation injury can lead to Reactive Airway Dysfunction Syndrome (RADS), within hours ${ }^{18}$. A case has been reported where a worker splashed in the face with formic acid developed respiratory distress and dysphagia, and died within 6 hours.

Acetic acid, in contrast, is a weak acid, which is also colourless with a pungent odour. The substance is corrosive to the eyes, skin, respiratory tract and gastrointestinal tract. Inhalation may cause lung oedema, which is a late manifestation ${ }^{19}$. In a study done to evaluate acute irritation during controlled exposure to vapours of acetic acid, no significant exposure related effects on pulmonary function was seen ${ }^{20}$. However pulmonary effects are seen in workers exposed to higher concentrations of acetic acid. In a setting where, a total of 56 hospital employees were exposed to glacial acetic acid after an accidental chemical spill, 0\% subjects with low exposure, $3.3 \%$ with medium exposure, and $21.4 \%$ with high exposure, developed RADS. ${ }^{21}$ Reversible airways obstruction and steroid responsive interstitial pneumonitis has been reported after exposure to glacial acetic acid. However case reports on deaths due to acetic acid inhalation injury are rare in the medical literature.

According to the Experimental officer, Rubber Research Institute, Sri Lanka (personal communication, A. K. D. Warnajith), both formic acid and acetic acid are used in the rubber industry. However the concentration of formic acid used in the rubber industry is $1 \%$, whereas $85 \%$ formic acid is freely available in the market. Similarly $98-100 \%$ acetic acid is available in the market though only $2 \%$ acetic acid is used in the rubber industry.

Out of the two acids formic acid is the most commonly used acid. Rubber research institute encourages the use of formic acid because of its anti-fungal effects but the popularity of formic acid may also be due to its low price. However the potential health effects of formic acid is far more lethal than that of acetic acid. Therefore, if concentrated formic acid was not available to the general public this death could have been averted.

In our patient the chemical nature or the strength of the acid was never ascertained; being referred to as rubber acid. Establishing the type of acid involved, would have been important in predicting the course of the disease, though it may not have affected the management. But it is of great 
importance to the forensic pathologist, to know the exact acid involved, since the course and the severity of the disease changes with the acid.

In most cases of inhalation injury, as in this patient, only a few signs of inhalation injury are found on admission. But these patients tend to develop a prolonged clinical course requiring long term artificial ventilation and severe pulmonary complications ${ }^{22}$.

\section{RECOMMENDATIONS}

The rubber industry and the general public need to be informed about the serious health consequences of Formic acid in comparison to Acetic acid. The support of the rubber research institute and the government should be enlisted to restrict the availability of both $85 \%$ formic acid and $98-100 \%$ acetic acid to the general population. Strict regulations should be introduced for sale and distribution of the concentrated acids. The use of acetic acid in the rubber industry should be encouraged and formic acid phased out.

Inhalation injury should be suspected, especially in cases of facial burns, and treatment should not be delayed.

\section{REFERENCES}

1. White CS, Templeton PA. Chemical pneumonitis. Radiology Clinics of North America. 1992;30:12311243

2. Rajan KG, Davies BH. Reversible airways obstruction and interstitial pneumonitis due to acetic acid. British Journal of Industrial Medicine.1989; 46: 67-68.

3. Bennion JR, Franzblau A. Chemical pneumonitis following household exposure to hydrofluoric acid. American Journal of Industrial Medicine.1997;31:474478.

4. Eddleston M. Patterns and problems of deliberate self-poisoning in the developing world. QJM: An International Journal of Medicine. 2000; 93.

5. Perera V, Karunadasa K, Perera C. Self-inflicted formic acid burn: rare form of acid burn (two case reports). European Journal of Plastic Surgery. 2010. In press.
6. De Alwis LBL. Lecture notes in forensic medicine. V.1. Sri Lanka: LBL Alwis,2007:172-173

7. Babapulle CJ. Clinical and forensic toxicology. Sri Lanka: Stamford lake,2001:199

8. Karunadasa KP, Perera C, Kanagaratnum V, Wijerathne UP, Samarasingha I, Kannangara CK. Burns due to Acid Assaults in Sri Lanka. Journal of Burn Care \& Research. 2010; 31: 781-785.

9. Cotran RS, Kumar V, Collins T. Robbins pathological basis of disease. $6^{\text {th }}$ ed. India: Harcourt; 2000

10. International Programme on Chemical Safety, Formic acid, 2005, http://www.inchem.org/documents/icsc/icsc/ eics0485.htm, accessed July 2011.

11. United states department of labour, Occupational Safety and Health Administration (OSHA), Occupational Safety and Health Guideline for Formic Acid, Washington, OSHA publication.

12. Sigurdsson J, Björnsson A, Gudmundsson ST. Formic acid burn--local and systemic effects: Report of a case. Burns. 1983; 9:358-61.

13. Theodore CC, Saralyn RW, Clark RF. Formic Acid Skin Burns Resulting in Systemic Toxicity. Annals of Emergency Medicine. 1995; 26:383-386.

14. Hathaway GJ, Proctor NH, Hughes JP, Fischman ML. Proctor and Hughes' chemical hazards of the workplace. New York: Van Nostrand Reinhold, 1991.

15. Rajan N, Rahim R, Kumar SK. Formic acid poisoning with suicidal intent: a report of 53 cases. Postgraduate Medical Journal. 1985; 61:35-36.

16. Jefferys DB, Wiseman HM. Formic acid poisoning. Postgraduate Medical Journal, 1980; 56:761-762.

17. Mathew AJ, Dalus D. Acute formic acid poisoning in south india, Postcards from Beijing: Annual Meeting Abstracts. Journal of Medical Toxicology. 2010;6:361

18. Yelon JA, Simpson RL, Gudjonsson O. Formic acid inhalation injury: a case report. Journal of burn care and rehabilitation. 1996; 17: 241-2.

19. International Programme on Chemical Safety. Acetic acid [Internet] 2005 [Peer review 2010]. Available from: http://www.inchem.org/documents/icsc/icsc/eics0363.ht $\mathrm{m}$

20. Ernstgarda L, Iregrenb A, Sjögrena B, Johansona G. Acute effects of exposure to vapours of acetic acid in humans. Toxicology Letters. 2006; 165: 22-30.

21. Kern DG. Outbreak of reactive airways dysfunction syndrome after a spill of glacial acetic acid. American Review of Respiratory Disease. 1991; 144: 1058-1064.

22. Wolter TP, Fuchs PC, Witzel C, Pallua N. Fumes in industrial fires can make inhalation injury more severea report of three cases of industrial burn accidents. Burns. 2005; 31:925-929. 